\title{
Dynamic Model of the Hot Strip Rolling Mill Vibration Resulting from Entry Thickness Deviation and Its Dynamic Characteristics
}

\author{
Xinxin Wang and Xiaoqiang Yan $(\mathbb{D}$ \\ School of Mechanical Engineering, University of Science and Technology Beijing, Beijing 100083, China \\ Correspondence should be addressed to Xiaoqiang Yan; yanxq@ustb.edu.cn
}

Received 30 October 2018; Revised 14 January 2019; Accepted 13 February 2019; Published 25 February 2019

Academic Editor: Denis Benasciutti

Copyright ( 2019 Xinxin Wang and Xiaoqiang Yan. This is an open access article distributed under the Creative Commons Attribution License, which permits unrestricted use, distribution, and reproduction in any medium, provided the original work is properly cited.

\begin{abstract}
The vibration demolding of the crystallizer leads to slab thickness deviation in continuous casting processes. Therefore, in this paper, the dynamic model of the hot strip rolling mill vibration resulting from entry thickness deviation is proposed and its dynamic characteristics are studied. First, the dynamic model of vertical vibration in the hot strip rolling mill is established based on Sims' rolling force model. Then, the model validity is certified by comparing the simulation with field test data from a 1580 hot strip rolling mill. Finally, we investigate the influence of model parameters on the dynamic characteristics of hot strip rolling mill vibration resulting from entry thickness deviation. The result indicates that hot strip rolling mill vibration resulting from entry thickness deviation can be reduced by increasing the area of the hydraulic cylinder piston side and the entry thickness as well as by decreasing the deformation resistance, rolling speed, and equivalent stiffness.
\end{abstract}

\section{Introduction}

It is well known that mill vibration has become a bottleneck in thin steel strip manufacturing and a global problem [1]. Rolling mill vibration can cause unacceptable thickness variation and severely damage mill equipment. Due to its complexity, the mechanism of rolling mill vibration is unclear and remains an open problem worldwide. Rolling mill vibration research aims to analyze dynamic characteristics and obtain vibration suppression measures based on mathematical modeling and data-driven methods.

Regarding mathematical models, there are two common methods used to study the dynamic characteristics of rolling mill vibration. The first method is establishing a spring mass model or dividing the continuum into finite elements, with various degrees of simplification, to solve for the inherent frequency and the mode of vibration. Peng et al. [2] established a swing dynamic model of the roll system with the dynamic characteristics of the hot rolling process and the coupling relationship between the horizontal and vertical vibrations of the work roll. Kim et al. [3] proposed a mathematical model of a cold rolling mill by considering the friction forces between rolls and the contact stiffness caused by roller bearings and rolls. Zheng et al. [4] analyzed the spatial vibration of four-high rolling mills using the modified Riccati-transfer matrix method (Riccati-TMM) and the finite element method (FEM). Liu et al. [5] studied the vertical vibration of the strip mill using the piecewise nonlinear constraint arising from hydraulic cylinder. Gao et al. [6] simplified the rolling mill structure into an eight-degree-offreedom (8-dof) spring mass model and analyzed the critical rolling speed using the stability criterion. The second method analyzes the rolling deformation zone to obtain its dynamic characteristics based on the Kalman equation or the Orowan equation. Yun [7] and $\mathrm{Hu}[8,9]$ et al. proposed a classical dynamic model of cold rolling mill vibration, which considered the change in the roll spacing and the rate of change of the roll spacing. Pittner et al. [10-12] proposed a dynamic model of the hot rolling mill, which could be applied only to looper control analysis and not to vertical vibration analysis. Fan et al. [13] proposed a dynamic model of hot rolling mill vertical vibration to analyze the influence of rolling process 
parameters on the hot rolling mill vibration. Zeng et al. [14] formulated a dynamic rolling process model based on the Bland-Ford-Hill rolling force model and analyzed the influences of process parameters and structure parameters on system stability. Based on the Coulomb friction model and the Kalman differential equation, Liu $[15,16]$ established a dynamic rolling process model that considered the rolled piece hardening effect and the work roll flattening effect.

Due to the vibration demolding of the crystallizer the slab presents the thickness deviation. It is necessary to study the effect of entry thickness deviation on hot rolling mill vibration. However, all above-mentioned models cannot be used to study the effect of entry thickness deviation on hot rolling mill vibration. Therefore, we propose a vertical vibration dynamic model of the hot strip rolling mill based on Sims' rolling force model $[17,18]$ to study dynamic characteristics of hot strip rolling mill vibration resulting from entry thickness deviation. In Section 2, the detailed derivation process of the dynamic model is shown and the dynamic model is presented in a state-space form. In Section 3, a comparison between the numerical simulation and the field test data certifies the dynamic model validity. In Section 4, we analyze the influence of model parameters, such as deformation resistance, entry thickness, rolling speed, equivalent stiffness, and the area of the hydraulic cylinder piston side, on dynamic characteristics of the hot rolling mill vibration resulting from the entry thickness deviation. The conclusion is given in Section 5 .

\section{Dynamic Model}

2.1. Mill Structure Dynamic Model. Generally the mill structure, which includes the rack, rollers, and the hydraulic cylinder, is described as a 5-dof lumped-mass model. For simplicity, the upper backup roll and the cylinder body are assumed to form a whole, and the piston rod and the mill rack are assumed to form a whole. As the servo valve adjusts only the pressure of the piston side and does not change the pressure of the rod side, the pressure of the rod side can be assumed to be constant. In addition, the lower part of the rack is assumed to be the ground. The schematic diagram of the mill structure is depicted in Figure 1.

To study vibration, only the dynamic parts of parameters are considered in our model. According to vibration and fluid theories, the kinetic equations of the mill structure are written as follows.

$$
\begin{aligned}
& m_{1} \frac{d^{2} x_{1}}{d t^{2}}+c_{1} \frac{d x_{1}}{d t}+k_{1} x_{1}=-p_{p} A_{p} \\
& A_{p}\left(\frac{d x_{2}}{d t}-\frac{d x_{1}}{d t}\right)+\frac{V_{p}}{\beta_{e}} \frac{d p_{p}}{d t}+c_{h} p_{p}=0 \\
& m_{2} \frac{d^{2} x_{2}}{d t^{2}}+c_{2}\left(\frac{d x_{2}}{d t}-\frac{d x_{3}}{d t}\right)+k_{2}\left(x_{2}-x_{3}\right)=p_{p} A_{p} \\
& m_{3} \frac{d^{2} x_{3}}{d t^{2}}+c_{2}\left(\frac{d x_{3}}{d t}-\frac{d x_{2}}{d t}\right)+k_{2}\left(x_{3}-x_{2}\right)=-d F_{R}
\end{aligned}
$$

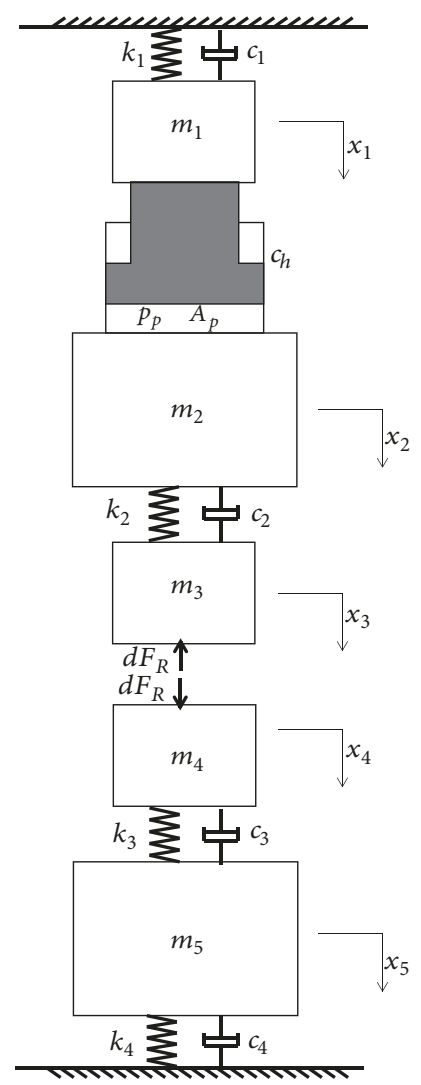

FIGURE 1: Schematic diagram of the mill structure.

$$
\begin{aligned}
& m_{4} \frac{d^{2} x_{4}}{d t^{2}}+c_{3}\left(\frac{d x_{4}}{d t}-\frac{d x_{5}}{d t}\right)+k_{3}\left(x_{4}-x_{5}\right)=d F_{R} \\
& m_{5} \frac{d^{2} x_{5}}{d t^{2}}+c_{3}\left(\frac{d x_{5}}{d t}-\frac{d x_{4}}{d t}\right)+k_{3}\left(x_{5}-x_{4}\right)+c_{4} \frac{d x_{5}}{d t} \\
& +k_{4} x_{5}=0
\end{aligned}
$$

where $m_{1}$ and $x_{1}$ are the equivalent mass and the displacement of the rack, respectively; $m_{2}$ and $x_{2}$ are the equivalent mass and the displacement of the upper backup roll, respectively; $m_{3}$ and $x_{3}$ are the equivalent mass and the displacement of the upper work roll, respectively; $m_{4}$ and $x_{4}$ are the equivalent mass and the displacement of the bottom work roll, respectively; $m_{5}$ and $x_{5}$ are the equivalent mass and the displacement of the bottom back roll, respectively; $k_{1}$ and $c_{1}$ are the equivalent stiffness and damping, respectively, between the rack and the ground; $k_{2}$ and $c_{2}$ are the equivalent stiffness and damping, respectively, between the upper work roll and the upper backup roll; $k_{3}$ and $c_{3}$ are the equivalent stiffness and damping, respectively, between the bottom work roll and the bottom back roll; $k_{4}$ and $c_{4}$ are the equivalent stiffness and damping, respectively, between the bottom back roll and the ground; $A_{p}$ is the area of the piston side; $p_{p}$ is the pressure of the piston side; $c_{h}$ is the internal leakage coefficient of the cylinder; $\beta_{e}$ is the elastic modulus of the liquid; and $d F_{R}$ is the dynamic part of the vertical rolling force. 


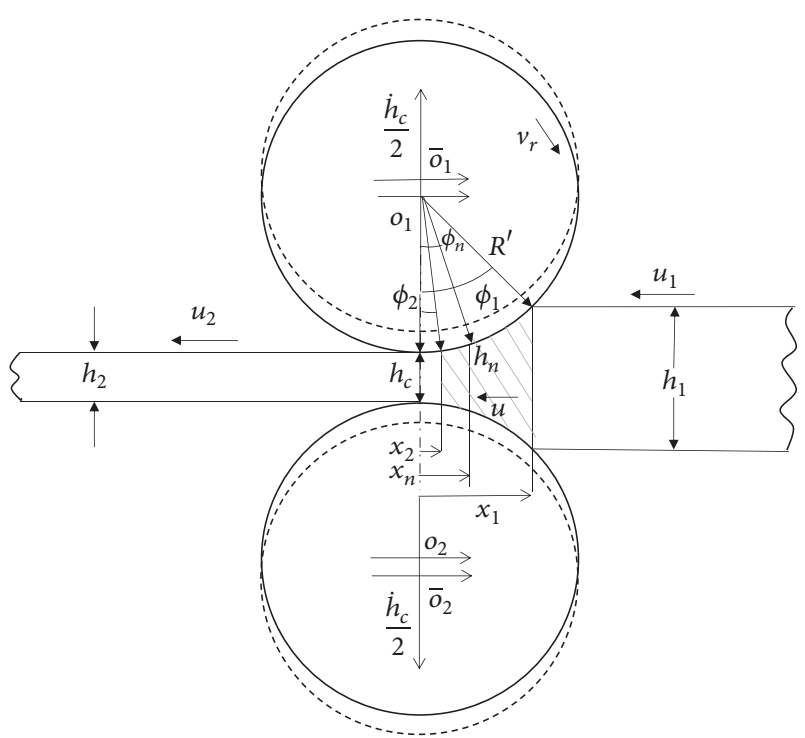

FIGURE 2: Roll bite geometry with vibration.

2.2. Rolling Process Dynamic Model. The slab method is one of the most widely used methods to describe the plastic deformation of rolled materials. Sims derived the specific roll force equation, which is often applied in hot rolling mills. In this section, based on the Sims' rolling force model, a dynamic rolling process model with vibration is proposed.

2.2.1. Strip Entry and Exit Position. The roll bite geometry with vibration is illustrated in Figure 2. It is assumed that the exit plane does not coincide with the centerline of the work rolls once the rolls begin to vibrate.

Here, $\bar{o}_{1}$ and $\bar{o}_{2}$ are the original work roll centers; $o_{1}$ and $o_{2}$ are the work roll centers with vibration; $h_{1}, h_{2}$, and $h_{n}$ are the strip entry thickness, the strip exit thickness, and the strip thickness of the neutral plane, respectively; $x_{1}, x_{2}$, and $x_{n}$ are the strip entry position, the strip exit position, and the neutral point position, respectively; $R^{\prime}$ is the deformed radius of the work roll; $u_{1}$ and $u_{2}$ are the strip speed at entry and exit, respectively; $\phi_{1}, \phi_{2}$, and $\phi_{n}$ are the strip entry angle, the strip exit angle, and the neutral angle, respectively; $v_{r}$ is the roll speed; $h_{c}$ is the roll gap spacing along the centerline of the work rolls; and $\dot{h}_{c}$ is the rate of change of the roll gap spacing.

The high rolling force causes the work roll deformation. According to the Hitchcock equation, the deformed radius is calculated as follows.

$$
R^{\prime}=R\left(1+\frac{8\left(1-v^{2}\right) F_{R}}{\pi E\left(h_{1}-h_{2}\right)}\right)
$$

where $R$ is the undeformed radius of the work roll; $v$ is Poisson's ratio; $E$ is Young's modulus; and $F_{R}$ is the total rolling force.

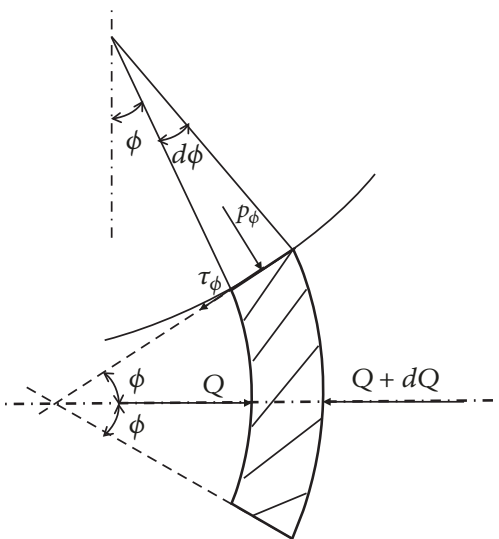

FIGURE 3: Stresses distribution acting on a volume element in the roll gap.

In the roll bite, the roll surface is usually assumed to be a parabolic curve. From Figure 2, the strip thickness at an arbitrary cross-section can be calculated by

$$
h=h_{\mathrm{c}}+\frac{x^{2}}{R^{\prime}}
$$

By combining (3), $x_{1}=R^{\prime} \sin \left(\phi_{1}\right)$, and $\sin \left(\phi_{1}\right) \approx \phi_{1}$, the strip entry angle can be derived from

$$
\phi_{1}=\sqrt{\frac{h_{1}-h_{c}}{R^{\prime}}}
$$

By applying the principle of mass conservation to the roll bite, the flow of metal through an arbitrary cross-section can be written as

$$
u h=u_{1} h_{1}-\left(x_{1}-x\right) \dot{h}_{c}
$$

By applying (5) to the neutral point position and the exit position, the corresponding mass conservation equations are listed as

$$
\begin{aligned}
& u_{2} h_{2}=u_{1} h_{1}-\left(x_{1}-x_{2}\right) \dot{h}_{c} \\
& u_{n} h_{n}=u_{1} h_{1}-\left(x_{1}-x_{n}\right) \dot{h}_{c}
\end{aligned}
$$

From Figure 2, the exit angle can be calculated by

$$
\phi_{2} \approx \tan \left(\phi_{2}\right)=\frac{\dot{h}_{c}}{2 u_{2}}
$$

By substituting both (3) and (6) into (7), the strip exit angle can be obtained.

$$
\phi_{2}=\frac{h_{c} \dot{h}_{c}}{2\left(v_{r} h_{c}+v_{r} x_{n}^{2} / R^{\prime}-x_{n} \dot{h}_{c}\right)}
$$

2.2.2. Neutral Point Position. Hot rolling mills roll with low tensions which can be neglected. The stress distribution in a volume element in the roll gap is illustrated in Figure 3, where 
the circumferential thickness of the slice is $d \phi$; the horizontal composite force acting on a cross-section is $Q$; the normal roll pressure is $p_{\phi}$; the specific shear stress is $\tau_{\phi}$; and the surface angularity is $\phi$.

According to Sims' method, the horizontal force equilibrium equation can be derived as

$$
\frac{d}{d \phi}\left(\frac{p_{\phi}}{k}-\frac{\pi}{4}\right)=\frac{R^{\prime} \pi \phi}{2\left(h_{c}+R^{\prime} \phi^{2}\right)} \pm \frac{R^{\prime}}{h_{c}+R^{\prime} \phi^{2}}
$$

where the constant $k$ is the deformation resistance of the arc of contact.

Equation (9) is solved by starting at the plane of exit and extending toward the plane of entry. Thus, the normal roll pressure between the exit position and the neutral point position is obtained.

$$
\begin{aligned}
p_{\phi} & =k\left[\frac{\pi}{4} \ln \left(\frac{h_{\phi}}{h_{2}}\right)+\frac{\pi}{4}+\sqrt{\frac{R^{\prime}}{h_{c}}} \tan ^{-1}\left(\sqrt{\frac{R^{\prime}}{h_{c}}} \phi\right)\right. \\
& \left.-\sqrt{\frac{R^{\prime}}{h_{c}}} \tan ^{-1}\left(\sqrt{\frac{R^{\prime}}{h_{c}}} \phi_{2}\right)\right]
\end{aligned}
$$

Equation (9) is solved by starting at the plane of entry and extending toward the plane of exit. Thus, the normal roll pressure between the entry position and the neutral point position is obtained.

$$
\begin{aligned}
p_{\phi} & =k\left[\frac{\pi}{4} \ln \left(\frac{h_{\phi}}{h_{1}}\right)+\frac{\pi}{4}+\sqrt{\frac{R^{\prime}}{h_{c}}} \tan ^{-1}\left(\sqrt{\frac{R^{\prime}}{h_{c}}} \phi_{1}\right)\right. \\
& \left.-\sqrt{\frac{R^{\prime}}{h_{c}}} \tan ^{-1}\left(\sqrt{\frac{R^{\prime}}{h_{c}}} \phi\right)\right]
\end{aligned}
$$

The neutral angle can be calculated by the equalization of the normal roll pressure obtained from (10) and (11) at the neutral point; the neutral angle can be calculated by

$$
\begin{aligned}
\phi_{n} & =\sqrt{\frac{h_{c}}{R^{\prime}}} \tan \left[\frac{\pi}{8} \sqrt{\frac{h_{c}}{R^{\prime}}} \ln \left(\frac{h_{2}}{h_{1}}\right)+\frac{1}{2} \tan ^{-1}\left(\sqrt{\frac{R^{\prime}}{h_{c}}} \phi_{1}\right)\right. \\
& \left.+\frac{1}{2} \tan ^{-1}\left(\sqrt{\frac{R^{\prime}}{h_{c}}} \phi_{2}\right)\right]
\end{aligned}
$$

2.2.3. Calculating Specific Roll Force. Notably, due to the small angular coordinate $\phi$ the differences between the normal roll pressure and the vertical pressure are negligible and the strip width is defined as unit width. When plane deformation occurs, the specific roll force can be calculated by

$$
F_{R}=R^{\prime} \int_{\phi_{2}}^{\phi_{1}} p_{\phi} d \phi
$$

By substituting (10) and (11) into (13), the specific roll force can be derived as

$$
\begin{aligned}
F_{R} & =R^{\prime} k\left[\frac{\pi}{4}\left(\phi_{2}-\phi_{1}\right)+\frac{\pi}{2} \sqrt{\frac{h_{c}}{R^{\prime}}} \tan ^{-1}\left(\sqrt{\frac{R^{\prime}}{h_{c}}} \phi_{1}\right)\right. \\
& -\frac{\pi}{2} \sqrt{\frac{h_{c}}{R^{\prime}}} \tan ^{-1}\left(\sqrt{\frac{R^{\prime}}{h_{c}}} \phi_{2}\right)+\frac{1}{2} \ln \left(\frac{h_{1}}{h_{2}}\right) \\
& \left.+\ln \left(\frac{h_{2}}{h_{n}}\right)\right]
\end{aligned}
$$

2.2.4. Linearized Dynamic Model of the Rolling Process. Since the vibration is dynamic rather than static, the variations in the system parameters are important. Linearization through first-order Taylor approximation can be used to simplify the dynamic model.

The variation in strip entry thickness $d h_{1}$, the variation in roll gap spacing $d h_{c}$, and the rate of change of roll gap spacing $d \dot{h}_{c}$ are defined as inputs, and the variation in specific roll force $d F_{R}$ is defined as an output.

From (14), the variation in specific roll force $d F_{R}$ can be expressed as

$$
d F_{R}=\frac{d F_{R}}{d h_{1}} d h_{1}+\frac{d F_{R}}{d h_{c}} d h_{c}+\frac{d F_{R}}{d \dot{h}_{c}} d \dot{h}_{c}
$$

where

$$
\begin{aligned}
\frac{d F_{R}}{d h_{1}} & =\frac{\partial F_{R}}{\partial h_{1}}+\frac{\partial F_{R}}{\partial \phi_{1}} \frac{\partial \phi_{1}}{\partial h_{1}}+\frac{\partial F_{R}}{\partial h_{n}} \frac{\partial h_{n}}{\partial \phi_{n}}\left(\frac{\partial \phi_{n}}{\partial h_{1}}+\frac{\partial \phi_{n}}{\partial \phi_{1}} \frac{\partial \phi_{1}}{\partial h_{1}}\right) \\
\frac{d F_{R}}{d h_{c}} & =\frac{\partial F_{R}}{\partial h_{c}}+\frac{\partial F_{R}}{\partial \phi_{1}} \frac{\partial \phi_{1}}{\partial h_{c}}+\frac{\partial F_{R}}{\partial h_{2}} \frac{\partial h_{2}}{\partial h_{c}}+\frac{\partial F_{R}}{\partial h_{n}}\left[\frac{\partial h_{n}}{\partial h_{c}}\right. \\
+ & \left.\frac{\partial h_{n}}{\partial \phi_{n}}\left(\frac{\partial \phi_{n}}{\partial \phi_{1}} \frac{\partial \phi_{1}}{\partial h_{c}}+\frac{\partial \phi_{n}}{\partial h_{2}} \frac{\partial h_{2}}{\partial h_{c}}+\frac{\partial \phi_{n}}{\partial h_{c}}\right)\right] \\
\frac{d F_{R}}{d \dot{h}_{c}} & =\left[\frac{\partial F_{R}}{\partial \phi_{2}}+\frac{\partial F_{R}}{\partial h_{2}} \frac{\partial h_{2}}{\partial \phi_{2}}\right. \\
+ & \left.\frac{\partial F_{R}}{\partial h_{n}} \frac{\partial h_{n}}{\partial \phi_{n}}\left(\frac{\partial \phi_{n}}{\partial \phi_{2}}+\frac{\partial \phi_{n}}{\partial h_{2}} \frac{\partial h_{2}}{\partial \phi_{2}}\right)\right] \frac{\partial \phi_{2}}{\partial \dot{h}_{c}}
\end{aligned}
$$

All partial derivatives in (16), (17), and (18) are listed in Appendix A.

2.3. State-Space Form of the Dynamic Model. The dynamic roll force from the rolling process acts on the work rolls and causes them to vibrate. The vibration of the work roll reacts to the rolling process. Clearly, there is coupling between the rolling process and the structure of the rolling mills. The 
coupling relationship between the work roll vibration and the dynamic roll gap spacing is shown as follows.

$$
\begin{aligned}
& h_{c}=x_{4}-x_{3} \\
& \dot{h}_{c}=\dot{x}_{4}-\dot{x}_{3}
\end{aligned}
$$

By combining (1), (15), and (19), the state space equation of the dynamic model whose system input is the entry thickness deviation can be written as

$$
\dot{X}=M_{1} X+M_{2} d h_{1}
$$

where

$$
\begin{aligned}
& X=\left[\begin{array}{lllllllllll}
x_{1} & \dot{x}_{1} & p_{p} & x_{2} & \dot{x}_{2} & x_{3} & \dot{x}_{3} & x_{4} & \dot{x}_{4} & x_{5} & \dot{x}_{5}
\end{array}\right]^{T} \\
& M_{1}
\end{aligned}
$$

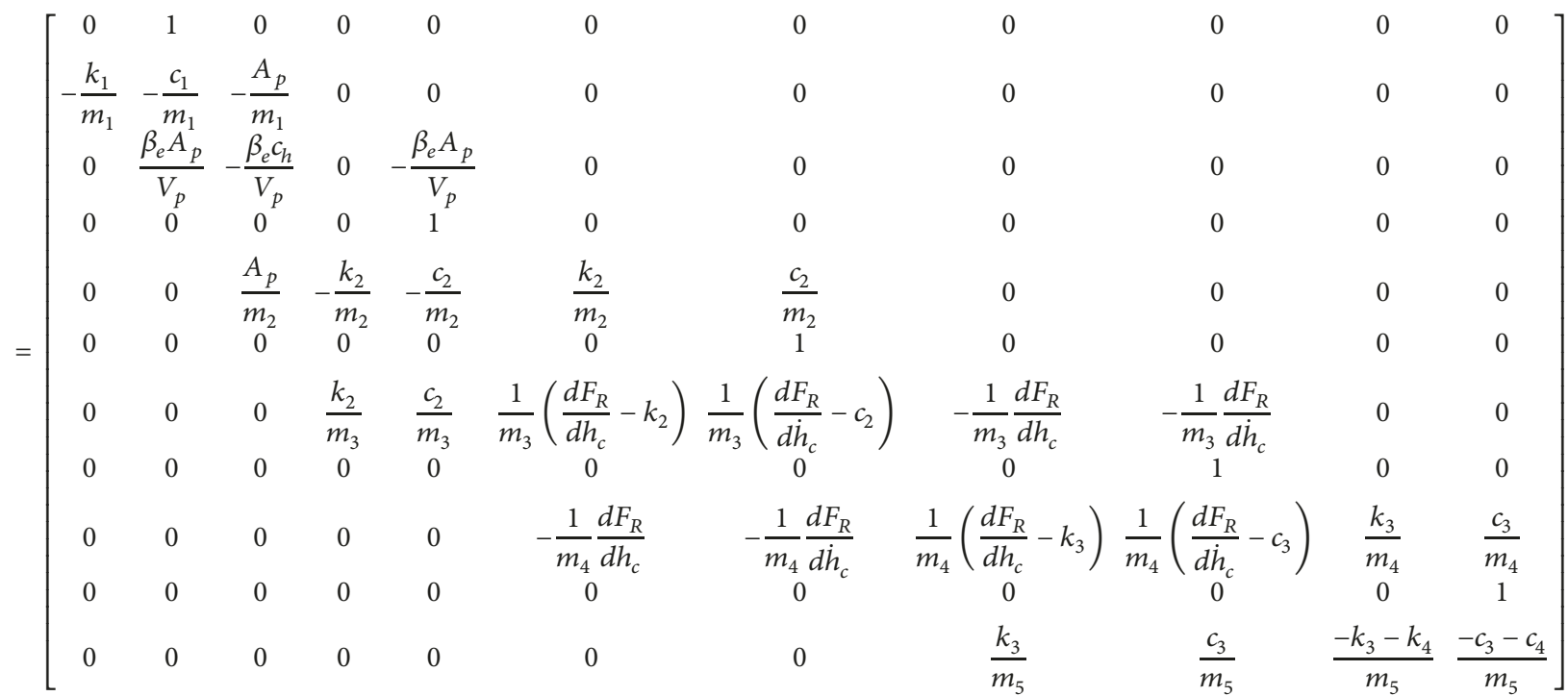

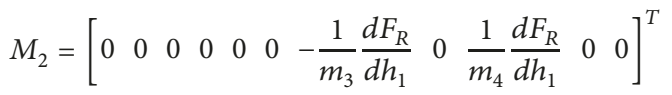

\section{Model Validity}

To verify model validity, numerical analysis results are compared with the field test data from F2 of a 1580 hot strip rolling mill. The experiment equipment is shown in Figure 4. It is a hot strip mill composed of seven stand 4-high rolling mills. The standard parameter settings are listed in Table 1. Equivalent mass and equivalent stiffness are calculated using the principle of conservation of energy [19]. Equivalent damping is assumed to be structural, and structural damping is proportional to equivalent stiffness [20]. The hydraulic cylinder parameters are found in the corresponding specification.

As the dynamic model of rolling mill vibration is formulated by coupling the rolling process model with the mill structure model, the validity of the rolling process model is first shown and then the validity of the dynamic model of rolling mill vibration is shown.

3.1. Validity of the Rolling Process Model. In the rolling process model, the specific rolling force is the most important parameter and can be measured by the load cells, which are installed between the bottom backup roll bearing and the lower housing. The specific roll force of F2 is treated as a criterion to evaluate the rolling process model. For four different types of steel products, the experimental data are compared with the numerical results, as listed in Table 2.

From Table 2, all errors between the experimental roll force and calculated roll force are less than $10 \%$ for different type of steel products, which shows that the rolling process model is effective.

3.2. Validity of the Rolling Mill Vibration Dynamic Model. The entry incoming thickness harmonic deviation is assumed to be excitation, its amplitude is $200 \mu \mathrm{m}$, and its frequency is 41 $\mathrm{Hz}$. In field manufacturing, the vibration velocity sensor on the up work roll is used to measure the work roll vibration. The up work roll vibration velocity is treated as a criterion to evaluate the rolling mill vibration intensity. It is known that many rolling process parameters, such as deformation resistance, reduction ratio, and entry thickness, play an important role in rolling vibration. However, it is impossible to change a single-factor variable in the field experiment. As a result, we choose three types of steel products, i.e., SPA$\mathrm{H}(1.52 \mathrm{~mm}), \mathrm{SPA}-\mathrm{H}(1.87 \mathrm{~mm})$, and FB60-P $(1.87 \mathrm{~mm})$ in Table 2, to qualitatively certify the validity of the rolling 
TABLE 1: Standard parameter settings.

\begin{tabular}{lccc}
\hline parameter & Value & parameter & value \\
\hline $\mathrm{R}$ & $0.375 \mathrm{~m}$ & $\beta_{e}$ & $1.4 \times 10^{9} \mathrm{~Pa}$ \\
$v_{r}$ & $2.89 \mathrm{~m} / \mathrm{s}$ & $V_{\mathrm{p}}$ & $3.46 \times 10^{-2} \mathrm{~m}^{3}$ \\
$\mathrm{E}$ & $2.06 \times 10^{11} \mathrm{~N} / \mathrm{m}^{2}$ & $c_{h}$ & $5 \times 10^{-14} \mathrm{~m}^{3} /(\mathrm{s} . \mathrm{Pa})$ \\
$v$ & 0.3 & $m_{1}$ & $1 \times 10^{4} \mathrm{~kg}$ \\
$h_{1}$ & $16.62 \mathrm{~mm}$ & $m_{2}$ & $3.6 \times 10^{4} \mathrm{~kg}$ \\
$h_{2}$ & $8.17 \mathrm{~mm}$ & $m_{3}$ & $2 \times 10^{4} \mathrm{~kg}$ \\
$\mathrm{k}$ & $201 \times 10^{6} \mathrm{~N} / \mathrm{m}^{2}$ & $m_{4}$ & $2 \times 10^{4} \mathrm{~kg}$ \\
$k_{1}$ & $4 \times 10^{9} \mathrm{~N} / \mathrm{m}$ & $m_{5}$ & $3.5 \times 10^{4} \mathrm{~kg}$ \\
$k_{2}$ & $2 \times 10^{10} \mathrm{~N} / \mathrm{m}$ & $c_{1}$ & $5 \times 10^{6} \mathrm{~N} /(\mathrm{m} / \mathrm{s})$ \\
$k_{3}$ & $2 \times 10^{10} \mathrm{~N} / \mathrm{m}$ & $c_{2}$ & $2 \times 10^{6} \mathrm{~N} /(\mathrm{m} / \mathrm{s})$ \\
$k_{4}$ & $4 \times 10^{9} \mathrm{~N} / \mathrm{m}$ & $c_{3}$ & $2 \times 10^{6} \mathrm{~N} /(\mathrm{m} / \mathrm{s})$ \\
$A_{p}$ & $0.8659 \mathrm{~m}^{2}$ & $c_{4}$ & $5 \times 10^{6} \mathrm{~N} /(\mathrm{m} / \mathrm{s})$ \\
\hline
\end{tabular}

TABLE 2: Comparison between the experimental data and the numerical results.

\begin{tabular}{|c|c|c|c|c|}
\hline Type of steel & SPA-H & SPA-H & SPHC & FB60-P \\
\hline F7 exit thickness (mm) & 1.52 & 1.87 & 2.6 & 1.87 \\
\hline F2 entry thickness (mm) & 16.62 & 16.62 & 20.72 & 18.09 \\
\hline F2 exit thickness $(\mathrm{mm})$ & 8.17 & 8.67 & 11.13 & 9.05 \\
\hline Deformation resistance $(\mathrm{MPa})$ & 201.11 & 190.47 & 150.28 & 181.96 \\
\hline Rolling speed(m/s) & 2.89 & 2.5 & 2.34 & 2.56 \\
\hline Reduction ratio (\%) & 50.8 & 47.8 & 46.3 & 50 \\
\hline Calculated roll force $(\mathrm{kN})$ & 22373 & 19769 & 15636 & 20051 \\
\hline Experimental roll force $(\mathrm{kN})$ & 23813 & 20390 & 14294 & 21332 \\
\hline Error of roll force (\%) & -6.05 & -3.05 & 8.58 & -6 \\
\hline
\end{tabular}

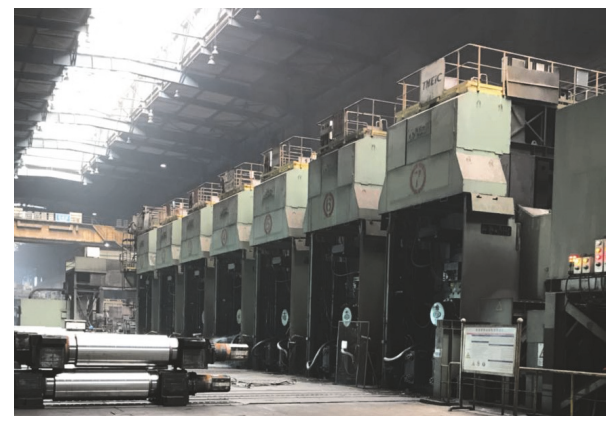

FIGURE 4: Experiment equipment.

mill vibration dynamic model. For these three specifications, simulation results of the upper work roll vibration velocity are shown in Figure 5, and the field test data of the upper work roll vibration velocity are shown in Figure 6.

From Figure 5, we can find that the vibration velocity amplitudes of SPA-H (1.52 mm), SPA-H (1.87 mm), and FB60$\mathrm{P}(1.87 \mathrm{~mm})$ are $4.153 \mathrm{~mm} / \mathrm{s}, 3.825 \mathrm{~mm} / \mathrm{s}$, and $3.61 \mathrm{~mm} / \mathrm{s}$, respectively, in the numerical simulation. From Figure 6, we can find that the vibration velocity amplitudes of SPA-H (1.52 $\mathrm{mm})$, SPA-H $(1.87 \mathrm{~mm})$, and FB60-P $(1.87 \mathrm{~mm})$ are 4.681 $\mathrm{mm} / \mathrm{s}, 4.129 \mathrm{~mm} / \mathrm{s}$, and $3.795 \mathrm{~mm} / \mathrm{s}$, respectively, in the field test data. The comparison between SPA-H $(1.87 \mathrm{~mm})$ and FB60-P (1.87 mm), which have the same F7 exit thickness and different steel grade, shows that the vibration velocity amplitude of FB60-P $(1.87 \mathrm{~mm})$ is $5.6 \%$ and $10.4 \%$ less than that of SPA-H $(1.87 \mathrm{~mm})$ in the numerical simulation and in the field test data, respectively. Similarly, the comparison between SPA-H $(1.87 \mathrm{~mm})$ and SPA-H $(1.52 \mathrm{~mm})$, which have different F7 exit thickness and the same steel grade, shows that the vibration velocity amplitude of SPA-H $(1.87 \mathrm{~mm})$ is $8 \%$ and $12 \%$ less than that of SPA-H $(1.52 \mathrm{~mm})$ in the numerical simulation and in the field test data, respectively. The vibration velocity amplitudes of SPA-H (1.52 mm), SPA$\mathrm{H}(1.87 \mathrm{~mm})$, and FB60-P $(1.87 \mathrm{~mm})$ in the numerical simulation and in the field test data are counted in Figure 7, which shows that, although there is a quantitative error, the numerical simulation qualitatively agrees with the field test data.

\section{The Influence of Model Parameters on Vibration Resulting from Entry Incoming Thickness Deviation}

Since the validity of the dynamic model is qualitatively certified, it can be used to qualitatively analyze the influence of model parameters on the vibration resulting from the entry thickness deviation. The maximum and area of [20 $\mathrm{Hz}, 70 \mathrm{~Hz}$ ], i.e., the general range of the vibration frequency in hot rolling, in the magnitude-frequency plot serve as the criterion for evaluating the vibration dynamic characteristics. 

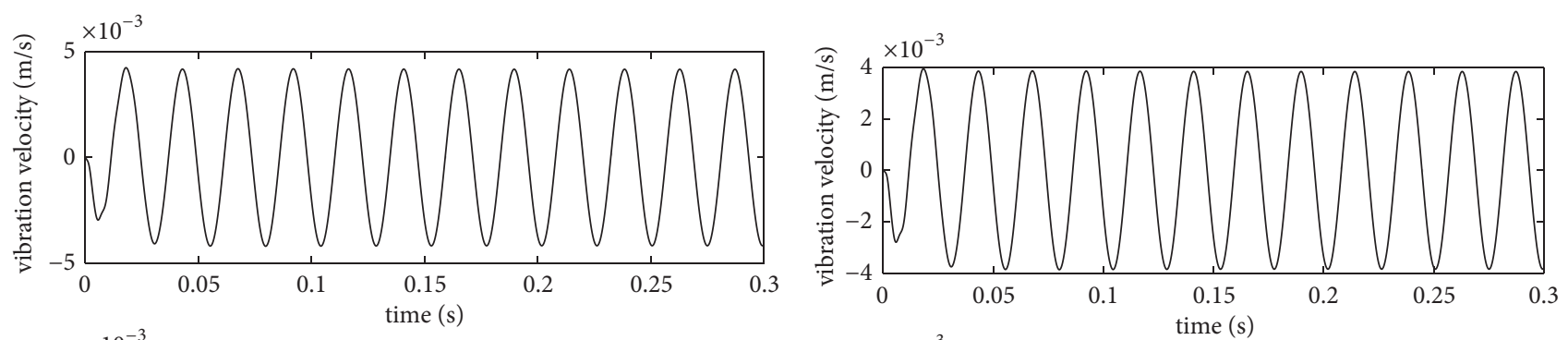

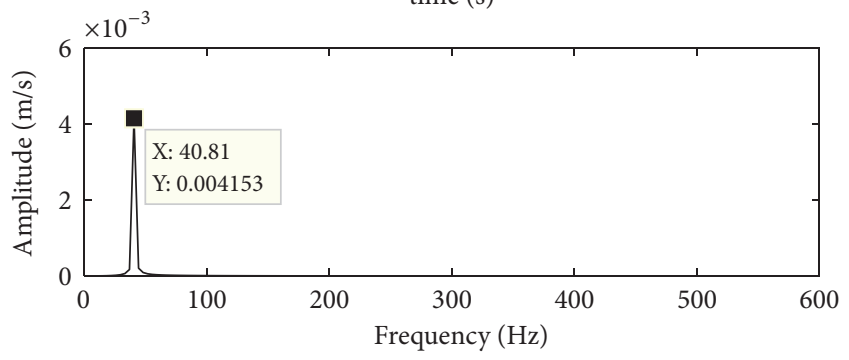

(a) SAP-H $(1.52 \mathrm{~mm})$

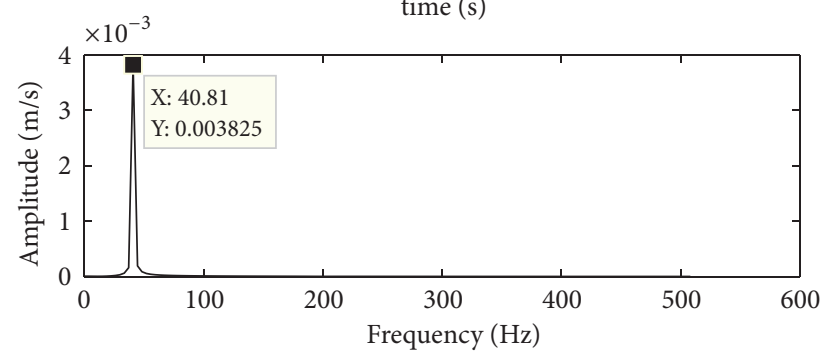

(b) SPA-H $(1.87 \mathrm{~mm})$
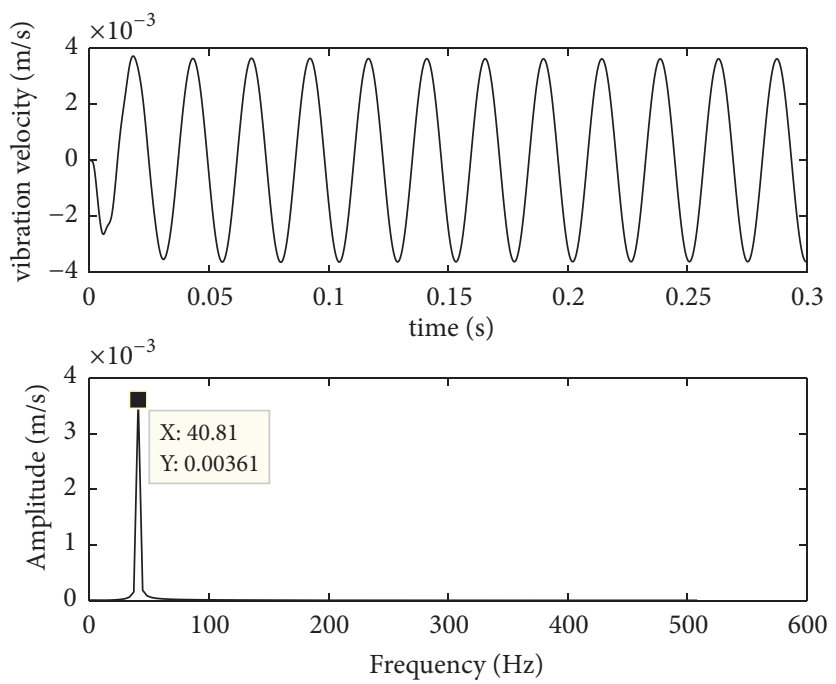

(c) FB60-P $(1.87 \mathrm{~mm})$

FigURE 5: Simulation results of the up work roll vibration velocity.

The lower maximum and the lower area result in the better vibration suppression. In this section, we take the model parameters of SPA-H $(1.52 \mathrm{~mm})$ as an example to qualitatively analyze the influence of model parameters, such as deformation resistance, entry thickness, rolling speed, equivalent stiffness, and the area of the piston side, on the vibration resulting from the entry thickness deviation.

4.1. Deformation Resistance. In the model parameters of SPA$\mathrm{H}(1.52 \mathrm{~mm})$ the deformation resistance is $201.11 \mathrm{MPa}$. Therefore, the range of the deformation resistance is set as $[150$ $\mathrm{MPa}, 250 \mathrm{MPa}$ ] and other parameters remain unchanged. The relationships between the deformation resistance and the maximum and area are shown in Figure 8, from which we find that the maximum and area increase with deformation resistance; i.e., as deformation resistance increases, vibration suppression decreases. With the same entry thickness deviation the bigger the deformation resistance, the bigger the dynamic rolling force.

4.2. Entry Thickness. In the model parameters of SPA-H (1.52 $\mathrm{mm}$ ) the entry thickness is $16.62 \mathrm{~mm}$, and the range of the entry thickness is set as [14 mm, $19 \mathrm{~mm}]$. The relationship between the entry thickness and the maximum and area is shown in Figure 9, from which we find that the maximum and the area decrease with increasing entry thickness; i.e., as entry thickness increases vibration suppression increases. The reduction ratio increases, which leads to the increase of the steady rolling force, but with the same entry thickness deviation, the bigger the entry thickness, the smaller the dynamic rolling force. 

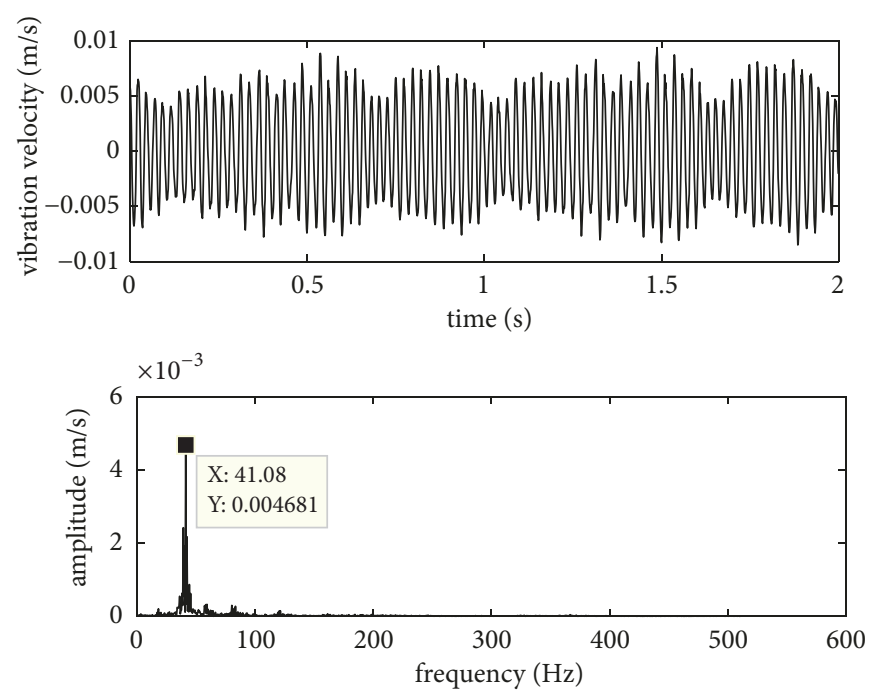

(a) SAP-H $(1.52 \mathrm{~mm})$
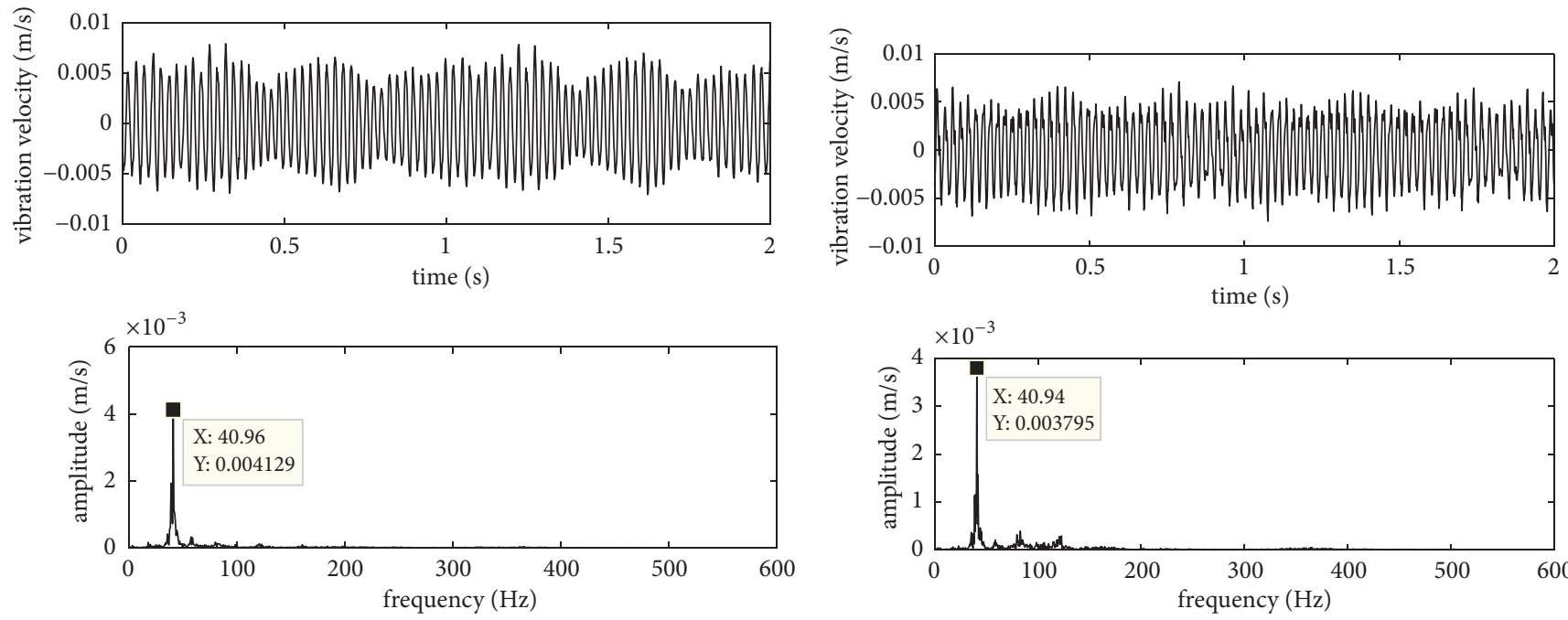

(b) SPA-H $(1.87 \mathrm{~mm})$

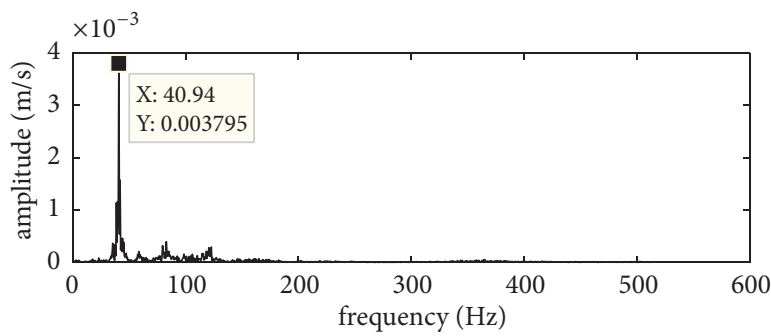

(c) FB60-P $(1.87 \mathrm{~mm})$

FIGURE 6: Field test data of the upper work roll vibration velocity.

4.3. Rolling Speed. In the model parameters of SPA-H (1.52 $\mathrm{mm}$ ), the rolling speed is $2.89 \mathrm{~m} / \mathrm{s}$, and the range of the rolling speed is set as $[2 \mathrm{~m} / \mathrm{s}, 4 \mathrm{~m} / \mathrm{s}]$. The relationships between the rolling speed and the maximum and area are shown in Figure 10, from which the maximum and area increase with rolling speed; i.e., as rolling speed increases, vibration suppression decreases. Due to the increase of rolling speed, the equivalent damping in roll gap $d F_{R} / d \dot{h}_{c}$ decreases, which increases the dynamic rolling force.

4.4. Area of the Piston Side. In the model parameters of SPA$\mathrm{H}(1.52 \mathrm{~mm})$ the area of the piston side is $0.8659 \mathrm{~m}^{2}$, and the range of the area of the piston side is set as $\left[0.6 \mathrm{~m}^{2}, 1 \mathrm{~m}^{2}\right]$. It should be noted that the volume of the piston side increases with the area of the piston side and the length of the piston side remains unchanged. The relationships between the area of the piston side and the maximum and area are shown in Figure 11, from which the maximum and area decrease with increasing area of the piston side. As the area of the piston side increases, hydraulic stiffness decreases. With the same entry thickness deviation, the smaller the hydraulic stiffness, the better the vibration suppression.

4.5. Equivalent Stiffness. The equivalent stiffness is classified into two categories: $k_{2}$ and $k_{3}$, which are $2 \times 10^{10} \mathrm{~N} / \mathrm{m}$ in the model parameters of SPA-H $(1.52 \mathrm{~mm}) ; k_{1}$ and $k_{4}$, which are $4 \times 10^{9} \mathrm{~N} / \mathrm{m}$ in the model parameters of SPA-H $(1.52 \mathrm{~mm})$. The range of $k_{2}$ and $k_{3}$ is set as $\left[1 \times 10^{10} \mathrm{~N} / \mathrm{m}, 3 \times 10^{10} \mathrm{~N} / \mathrm{m}\right]$ and the range of $k_{1}$ and $k_{4}$ is set as $\left[3 \times 10^{9} \mathrm{~N} / \mathrm{m}, 5 \times 10^{9} \mathrm{~N} / \mathrm{m}\right]$. The relationships between the equivalent stiffness and the maximum and area are shown in Figure 12, from which the maximum and area increase with equivalent stiffness. With 


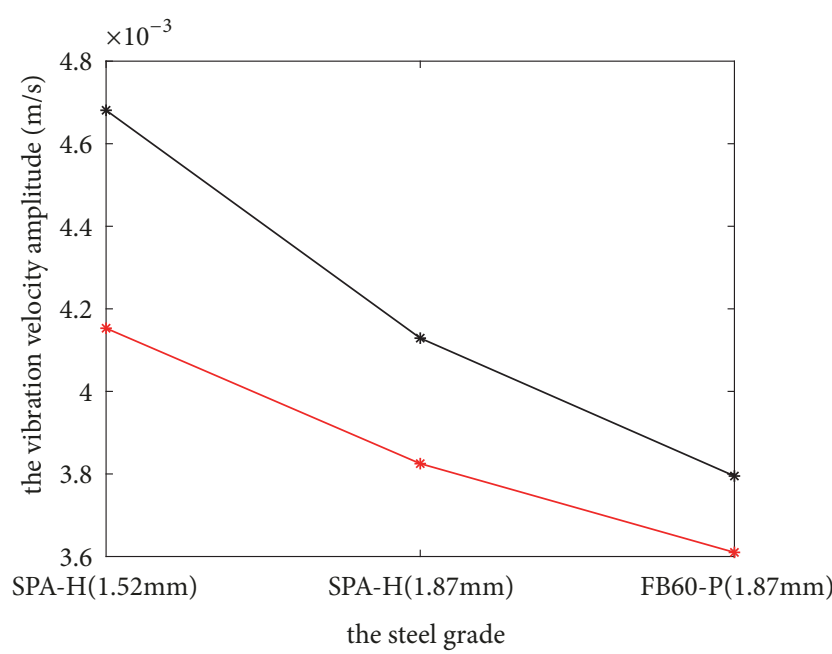

FIGURE 7: The count of all vibration velocity amplitudes.
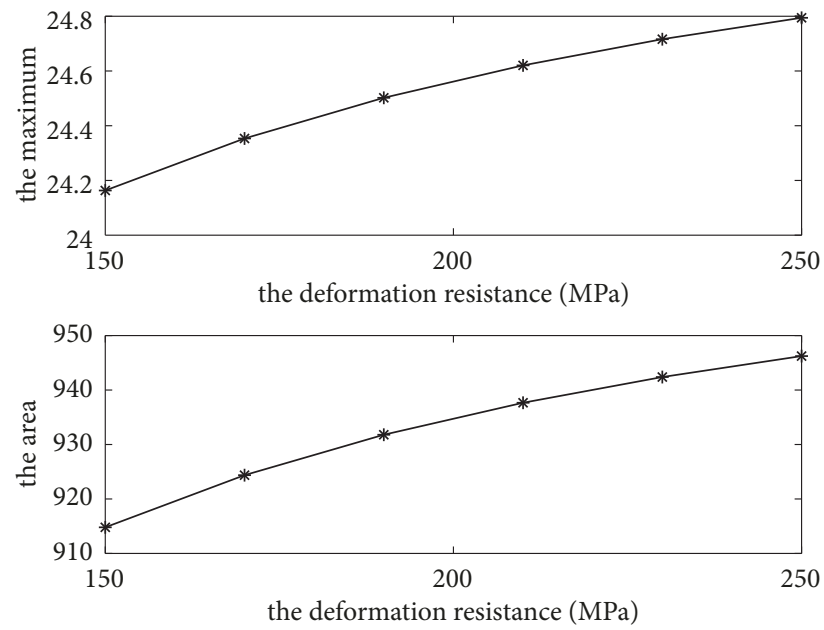

FIGURE 8: The influence of deformation resistance on vibration suppression.
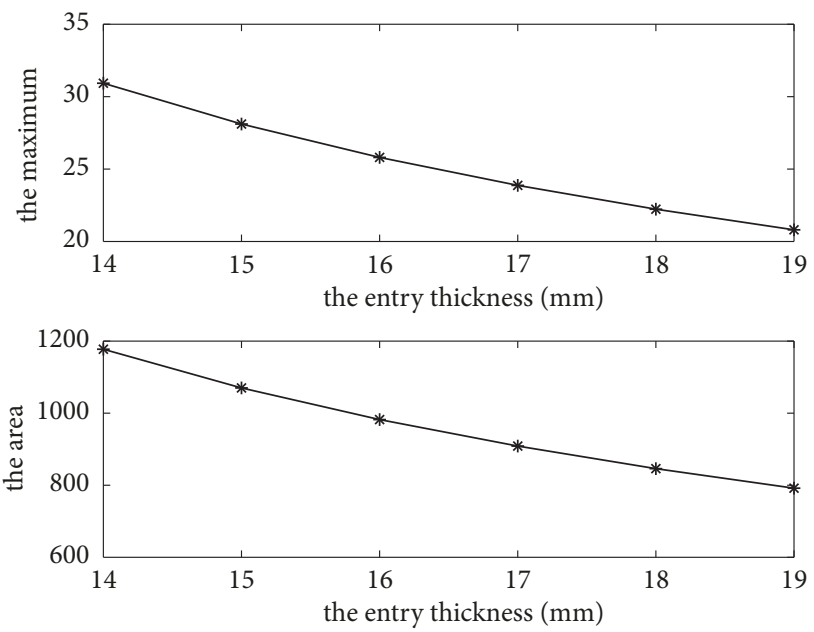

FIGURE 9: The influence of entry thickness on vibration suppression.
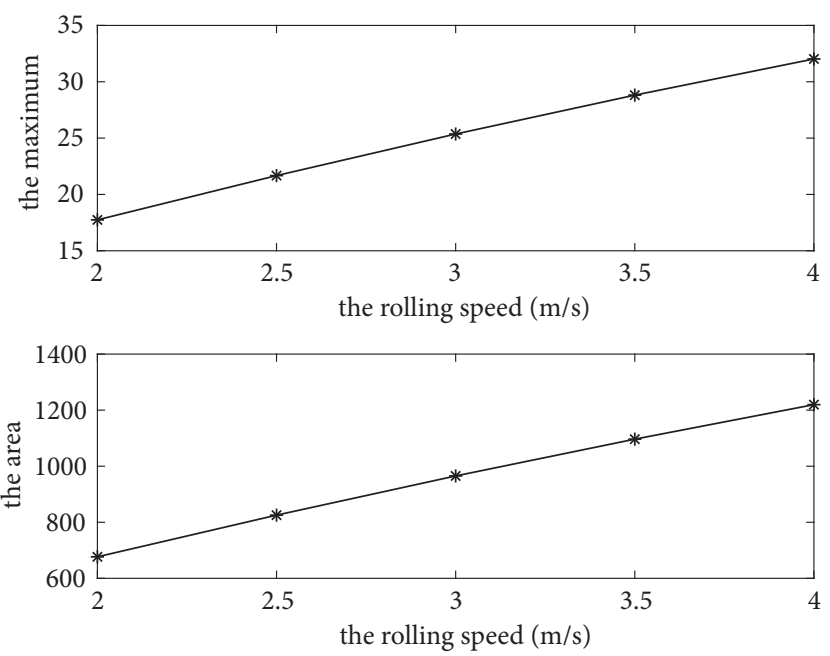

FIGURE 10: The influence of rolling speed on vibration suppression.

the same entry thickness deviation, the lower the equivalent stiffness, the smaller the impact force on the work roll, which leads to a smaller dynamic rolling force.

\section{Conclusion}

In this paper, the dynamic model of hot strip rolling mill vibration resulting from entry thickness deviation is proposed and its dynamic characteristic is studied. By means of mathematic modeling, numerical simulation, and field test data, the following conclusions are obtained.

(1) The proposed dynamic model, based on the Sims' rolling force, is effective and can be used to study the dynamic characteristics of hot rolling mill vibration resulting from the entry thickness deviation;

(2) The hot rolling mill vibration resulting from the entry thickness deviation decreases with decreasing deformation resistance and rolling speed, as well as increasing entry thickness;

(3) The hot rolling mill vibration resulting from the entry thickness deviation decreases with increasing area of the hydraulic cylinder piston side and decreasing equivalent stiffness.

\section{Appendix}

\section{A.}

For the sake of convenience in writing, the following definition is used.

$$
\begin{gathered}
\frac{\pi}{8} \sqrt{\frac{h_{c}}{R^{\prime}}} \ln \left(\frac{h_{2}}{h_{1}}\right)+\frac{1}{2} \tan ^{-1}\left(\sqrt{\frac{R^{\prime}}{h_{c}}} \phi_{1}\right) \\
+\frac{1}{2} \tan ^{-1}\left(\sqrt{\frac{R^{\prime}}{h_{c}}} \phi_{2}\right) \triangleq f f
\end{gathered}
$$



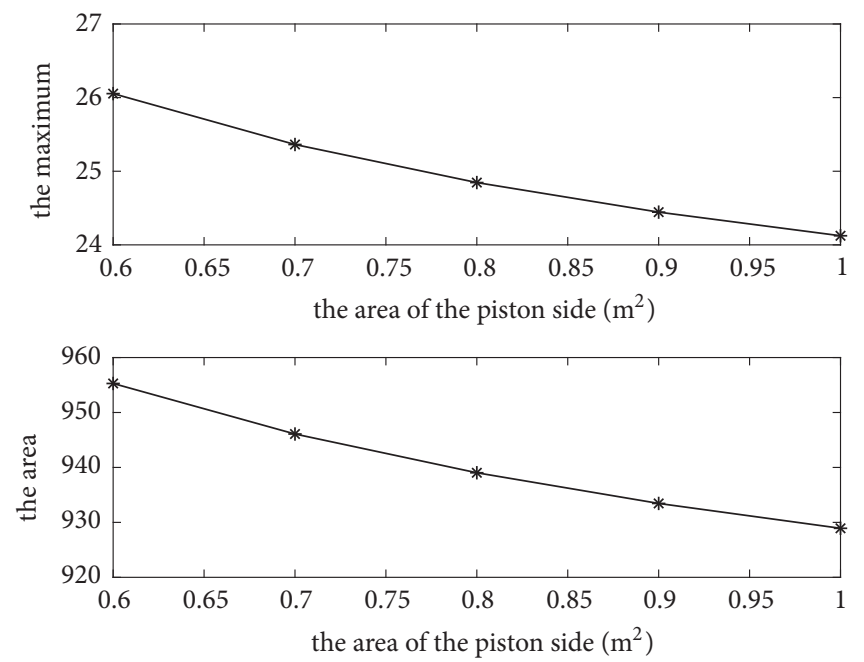

Figure 11: The influence of the area of the piston side on vibration suppression.
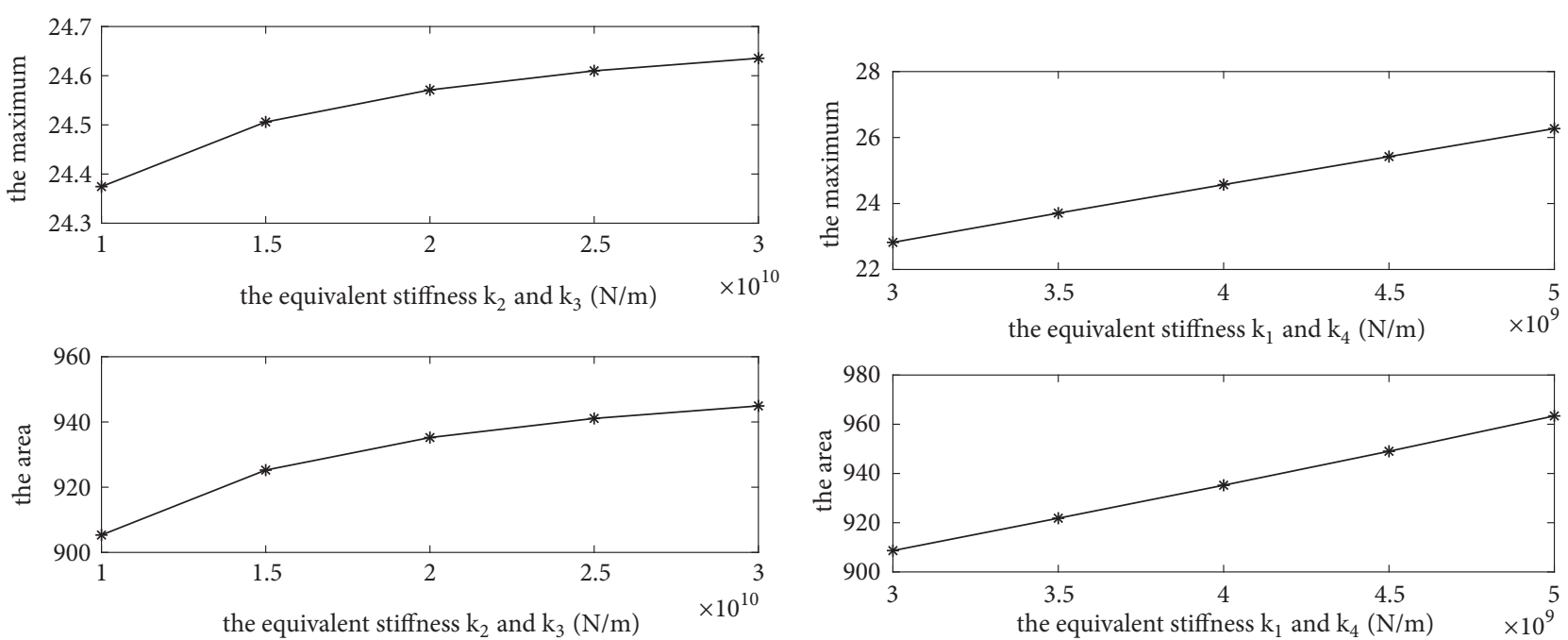

(a) $k_{2}$ and $k_{3}$

(b) $k_{1}$ and $k_{4}$

FIGURE 12: The influence of equivalent stiffness on vibration suppression.

All partial derivatives in (16), (17), and (18) are listed as follows.

$$
\begin{aligned}
& \frac{\partial F_{R}}{\partial h_{1}}=\frac{R^{\prime} k}{2 h_{1}} \\
& \frac{\partial F_{R}}{\partial \phi_{1}}=R^{\prime} k\left[\frac{\pi h_{c}}{2 h_{1}}-\frac{\pi}{4}\right] \\
& \frac{\partial \phi_{1}}{\partial h_{1}}=\frac{1}{2} \sqrt{\frac{1}{R^{\prime}\left(h_{1}-h_{c}\right)}} \\
& \frac{\partial F_{R}}{\partial h_{n}}=-\frac{R^{\prime} k}{h_{n}} \\
& \frac{\partial h_{n}}{\partial \phi_{n}}=2 R^{\prime} \phi_{n}
\end{aligned}
$$$$
\frac{\partial \phi_{n}}{\partial h_{1}}=-\frac{\pi h_{c}}{8 R^{\prime} h_{1} \cos ^{2}(f f)}
$$$$
\frac{\partial \phi_{n}}{\partial \phi_{1}}=\frac{h_{c}}{2 h_{1} \cos ^{2}(f f)}
$$$$
\frac{\partial \phi_{1}}{\partial h_{c}}=-\frac{1}{2} \sqrt{\frac{1}{R^{\prime}\left(h_{1}-h_{c}\right)}}
$$$$
\frac{\partial h_{2}}{\partial h_{c}}=1
$$$$
\frac{\partial h_{n}}{\partial h_{c}}=1
$$$$
\frac{\partial F_{R}}{\partial h_{2}}=\frac{R^{\prime} k}{2 h_{2}}
$$ 


$$
\begin{aligned}
\frac{\partial \phi_{n}}{\partial h_{2}} & =\frac{\pi h_{c}}{8 R^{\prime} h_{2} \cos ^{2}(f f)} \\
\frac{\partial F_{R}}{\partial h_{c}} & =R^{\prime} k\left\{\frac { \pi } { 4 \sqrt { R ^ { \prime } h _ { c } } } \left[\tan ^{1}\left(\sqrt{\frac{R^{\prime}}{h_{c}}} \phi_{1}\right)\right.\right. \\
& \left.\left.-\tan ^{1}\left(\sqrt{\frac{R^{\prime}}{h_{c}}} \phi_{2}\right)\right]+\frac{\pi}{4}\left(\frac{\phi_{2}}{h_{2}}-\frac{\phi_{1}}{h_{1}}\right)\right\} \\
\frac{\partial \phi_{n}}{\partial h_{c}} & =\frac{\tan (f f)}{2 \sqrt{h_{c} R^{\prime}}}+\frac{1}{\cos ^{2}(f f)}\left[\frac{\pi}{16 R^{\prime}} \ln \left(\frac{h_{2}}{h_{1}}\right)\right. \\
- & \left.\frac{1}{4}\left(\frac{\phi_{1}}{h_{1}}+\frac{\phi_{2}}{h_{2}}\right)\right] \\
\frac{\partial F_{R}}{\partial \phi_{2}} & =R^{\prime} k\left(\frac{\pi}{4}-\frac{\pi h_{c}}{2 h_{2}}\right) \\
\frac{\partial \phi_{2}}{\partial \dot{h}_{c}} & =\frac{h_{c}}{2 v_{r} h_{n}} \\
\frac{\partial h_{2}}{\partial \phi_{2}} & =2 R^{\prime} \phi_{2} \\
\frac{\partial \phi_{n}}{\partial \phi_{2}} & =\frac{h_{c}}{2 h_{2} \cos ^{2}(f f)}
\end{aligned}
$$

\section{Data Availability}

The data used to support the findings of this study are available from the corresponding author upon request.

\section{Conflicts of Interest}

The authors declare that they have no conflicts of interest.

\section{Acknowledgments}

This research is supported by the National Key Technology Support Program (No. 51775038).

\section{References}

[1] Z. Gao, Y. Zang, and L. Zeng, "Review of modelling and theoretical studies on chatter in the rolling mills," Jixie Gongcheng Xuebao/Journal of Mechanical Engineering, vol. 51, no. 16, pp. 87112, 2015.

[2] Y. Peng, M. Zhang, J.-L. Sun, and Y. Zhang, "Experimental and numerical investigation on the roll system swing vibration characteristics of a hot rolling mill," ISIJ International, vol. 57, no. 9, pp. 1567-1576, 2017.

[3] Y. Kim, H. Park, S. S. Lee, and C.-W. Kim, "Development of a mathematical model for the prediction of vibration in a cold rolling mill including the driving system," ISIJ International, vol. 52, no. 6, pp. 1135-1144, 2012.
[4] Y.-J. Zheng, G.-X. Shen, Y.-G. Li, M. Li, and H.-M. Liu, "Spatial vibration and its numerical analytical method of four-high rolling mills," Journal of Iron and Steel Research, International, vol. 21, no. 9, pp. 837-843, 2014.

[5] F. Liu, B. Liu, H.-R. Liu, Y.-L. Gong, and S.-J. Wang, "Vertical vibration of strip mill with the piecewise nonlinear constraint arising from hydraulic cylinder," International Journal of Precision Engineering and Manufacturing, vol. 16, no. 9, pp. 1891-1898, 2015.

[6] Z. Gao, L. Bai, and Q. Li, "Research on critical rolling speed of self-excited vibration in the tandem rolling process of thin strip," Jixie Gongcheng Xuebao/Journal of Mechanical Engineering, vol. 53, no. 12, pp. 118-132, 2017.

[7] I.-S. Yun, W. R. D. Wilson, and K. F. Ehmann, "Chatter in the strip rolling process, Part 1: Dynamic model of rolling," Journal of Manufacturing Science and Engineering, vol. 120, no. 2, pp. 330-336, 1998.

[8] P.-A. Hu, H. Zhao, and K. F. Ehmann, “Third-octave-mode chatter in rolling. Part 1: Chatter model," Proceedings of the Institution of Mechanical Engineers, Part B: Journal of Engineering Manufacture, vol. 220, no. 8, pp. 1267-1277, 2006.

[9] P.-H. Hu and K. F. Ehmann, "Dynamic model of the rolling process. Part I: Homogeneous model," The International Journal of Machine Tools and Manufacture, vol. 40, no. 1, pp. 1-19, 2000.

[10] S. K. Yildiz, J. F. Forbes, B. Huang et al., "Dynamic modelling and simulation of a hot strip finishing mill," Applied Mathematical Modelling, vol. 33, no. 7, pp. 3208-3225, 2009.

[11] J. Pittner and M. A. Simaan, "A useful control model for tandem hot metal strip rolling," IEEE Transactions on Industry Applications, vol. 46, no. 6, pp. 2251-2258, 2010.

[12] F.-C. Yin, D.-H. Zhang, and Y.-C. Zhang, "Dynamic modeling and rolling data analysis of the tandem hot rolling process," Simulation, vol. 93, no. 4, pp. 307-321, 2017.

[13] X. Fan, Y. Zang, and K. Jin, "Rolling process and its influence analysis on hot continuous rolling mill vibration," Applied Physics A: Materials Science \& Processing, vol. 122, no. 12, 2016.

[14] L. Zeng, Y. Zang, and Z. Gao, "Multiple-modal-coupling modeling and stability analysis of cold rolling mill vibration," Shock and Vibration, vol. 2016, Article ID 2347386, 26 pages, 2016.

[15] X. Liu, Modeling and Instability Mechanism of Self-excited Vibration during Continuous Cold Rolling Process, University of Science and Technology Beijing, Beijing, China, 2018.

[16] X. Liu, Y. Zang, Z. Gao, and L. Zeng, "Time delay effect on regenerative chatter in tandem rolling mills," Shock and Vibration, vol. 2016, Article ID 4025650, 15 pages, 2016.

[17] R. B. Sims, "The calculation of roll force and torque in hot rolling mills," Proceedings of the Institution of Mechanical Engineers, vol. 168, no. 1, pp. 191-200, 2006.

[18] M. Ataka, "Rolling technology and theory for the last 100 years: The contribution of theory to innovation in strip rolling technology," ISIJ International, vol. 55, no. 1, pp. 89-102, 2015.

[19] J. Zou and L. Xu, Tandem Mill Vibration Control, Metallurgical Industry Press, 1998.

[20] M. Mosayebi, F. Zarrinkolah, and K. Farmanesh, "Calculation of stiffness parameters and vibration analysis of a cold rolling mill stand," The International Journal of Advanced Manufacturing Technology, vol. 91, no. 9-12, pp. 4359-4369, 2017. 


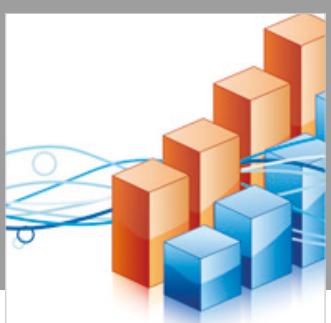

Advances in

Operations Research

\section{-n-m}
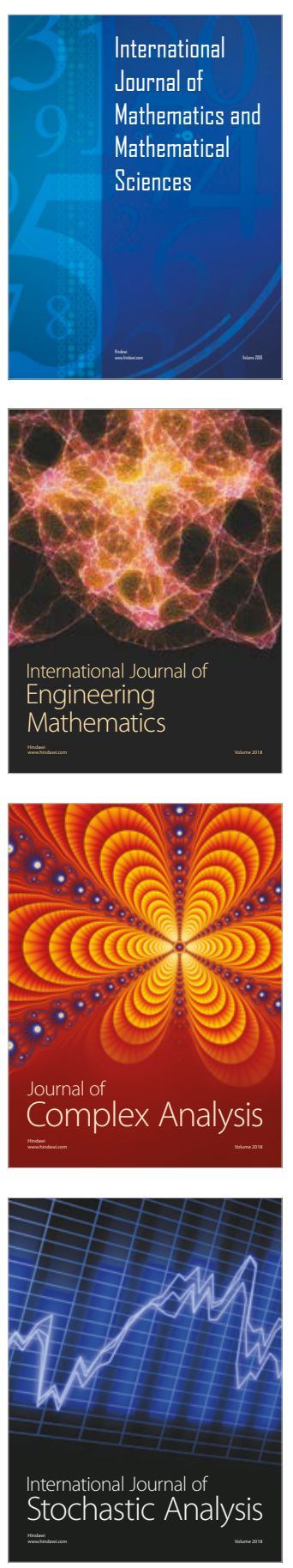
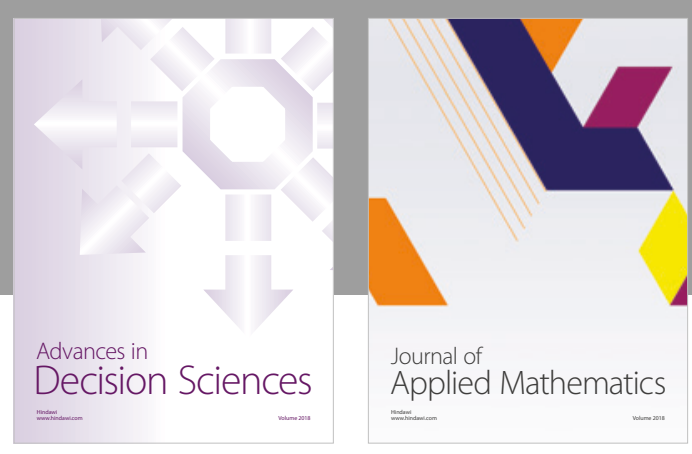

Journal of

Applied Mathematics
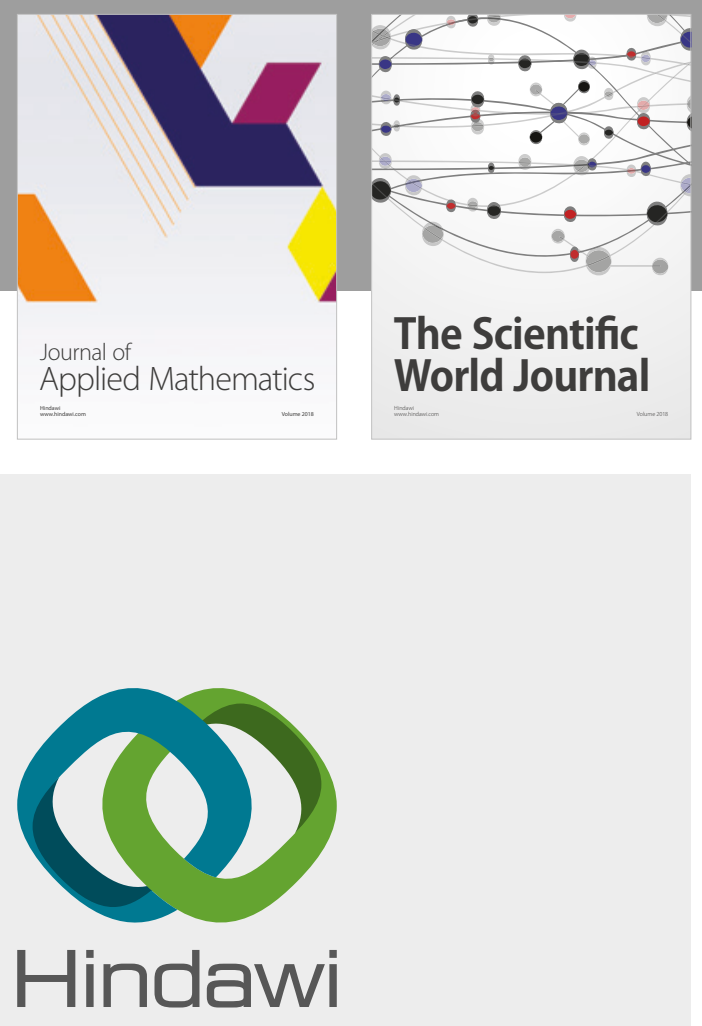

Submit your manuscripts at

www.hindawi.com

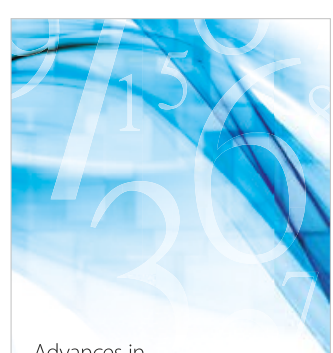

Advances in
Numerical Analysis
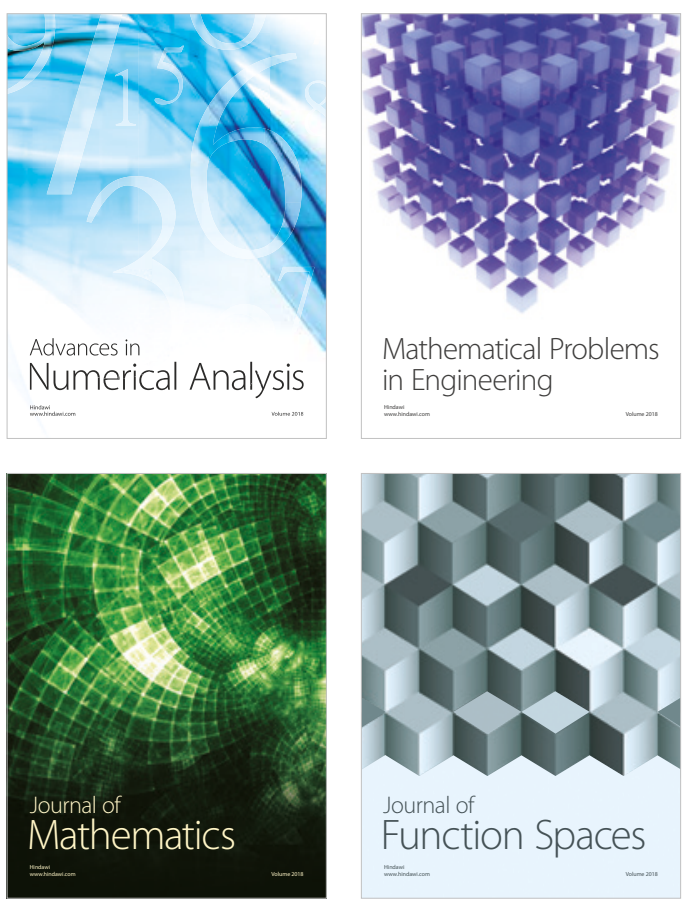

Mathematical Problems in Engineering

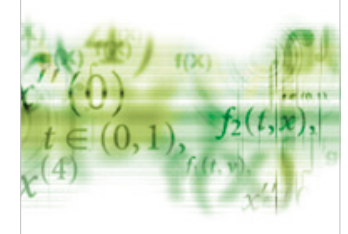

International Journal of

Differential Equations

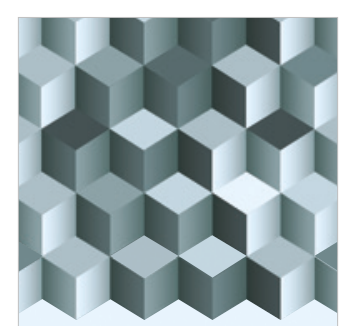

Journal of

Function Spaces

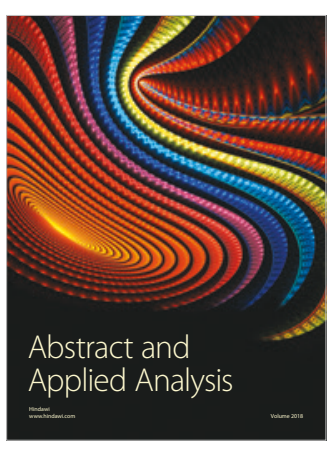

The Scientific

World Journal

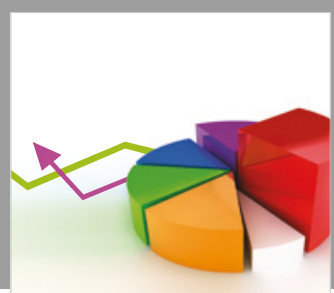

Journal of

Probability and Statistics
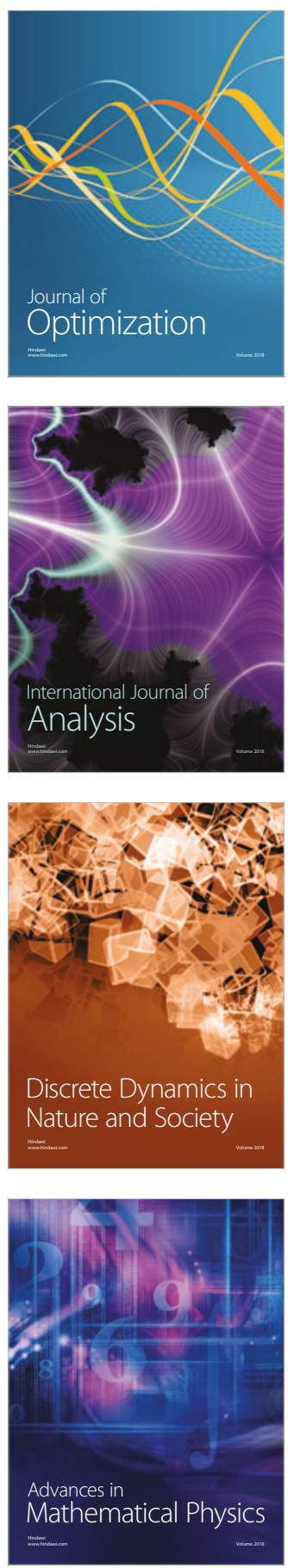